\title{
SOPHIA
}

PEER REVIEW JOURNAL

VISUAL SPACES OF CHANGE: DESIGNING INTERIORITY

SHELTER, SHAPE, PLACE, ATMOSPHERE

ISSN: 2183-8976 [PRINT] 2183-9468 [ONLINE]

Volume 5, Issue 1 | Publication year: 2020

DOI 10.24840/2183-8976_2020-0005_0001_3

(C) SCOPIO EDITIONS

HOMEPAGE: HTTPS://WWW.SOPHIAJOURNAL.NET

\section{PRESERVING HERITAGE THROUGH NEW NARRATIVES: DESIGNING A GUESTHOUSE WITHIN A CROSS-DISCIPLINARY TEAM}

Pedro Bandeira Maia and Raul Pinto

\begin{abstract}
The following article describes the ongoing interior design project that accommodates a guesthouse in a historical building located in the city of Coimbra in Portugal. It focuses on the importance of generating new narratives to maintain the original nineteenth century building's essence, when changing the architectural program, from a pharmacy on the ground floor and residences in the upper floors into a single guesthouse.

We present the design-led methodology focused on the importance of generating narratives as a foundation to achieve a common goal while working in a cross-disciplinary team. In this context, the designer not only has the role of the form-giver, but also becomes the mediator between matter and form, the team leader, and the forecaster of the user's emotional experiences. When adapting client's brief into a tangible outcome within a team that crosses various areas of expertise (in this case: architecture, design, engineering, archaeology, conservation, and restoration), the importance of generating an open concept that can adapt to the evolving context, becomes key to meet client's expectations. This article intends to contribute to the discussion of the designer's elastic mindset as a binding tool between actors and contexts, towards an outcome that acknowledges the importance of the contribution of each one when looking for enriched results. Therefore, it questions what is gained and what is lost by setting aside the classic design fundamental principles and by focusing on design as a managing tool between data and the involved actors for an enriched outcome.

As a main conclusion, it underlines the importance of generating a strong narrative with an open outcome to bind all stakeholders to a common goal through the designer as a project leader.
\end{abstract}

Keywords: interior design, interdisciplinary, narrative, experience, heritage 
Pedro Bandeira Maia (1975) opened in partnership with Raul Pinto the design studio EstúdioAma in 2003, focused on interior and product design. In 2002 he completed a degree in Equipment Design (EUAC-Coimbra), having followed a 6-month internship at Dâmaso Vidros de Portugal S.A. In 2006 completed postgraduate studies in Engineering Design (IST-Lisboa), in 2009 finished a master's degree in Aesthetic Communication (EUAC-Coimbra), and in 2011 obtained the title of Specialist in Product Design (IPC; IPL; UALG). In 2019 finished a PhD in Design at the University of Aveiro with the title "For a biological-inspired interaction design" focused on interaction design based on biological behaviors (with an emphasis on the product). He has been a professor since 2007 (I.P. Coimbra; I.P. Cávado e do Ave; U. Aveiro), currently teaching in the Degree of Art and Design (IPC) and in the Master in Design and Product Development (IPCA). He is member of ID+ (Institute of Research in Design, Media and Culture at the University of Aveiro and University of Porto).

Raul Pinto (1978) opened in partnership with Pedro Bandeira Maia the design studio EstúdioAma in 2003, focused on interior and product design. In 2003 graduated in Product Design (ARCAEUAC). In 2009 received his M.Sc. in Engineering Design (IST) and in 2011 the title of Specialist in Product Design (IPG; IPL; IPVC). Was Project Manager (Design Led Developer) at Design Factory Aveiro in Creative Science Park. Working as a lecturer since 2010 at IPG, IPV, UA in Portugal and currently at IEU in Turkey. He is currently a PhD candidate at the University of Aveiro where he is studying and working with biological generative systems, looking for alternative production tools aimed at customization. 


\section{Introduction}

The following article presents the design-led interior design project entitled the Soporific Guesthouse, for a small hotel that was commissioned to a design studio based in Aveiro', Portugal. The intention is not as much to present the project itself, but to describe the tools used to design and manage the process of converting an existing building into a specific functional and aesthetic program within an interdisciplinary team.

The following article begins by portraying the context of the existing building and identifying the respective project team, continues by describing the architectural program that serves as the basis for the different design options. It follows with a theoretical reflection on the role of the designer as a project leader in an interdisciplinary team, and on the importance of having an elastic-mind to bind all team members in pursuing a common outcome.

After the introduction and theoretical considerations, the article illustrates the importance of building a joint narrative that offers coherence to the design team and presents open outcomes as an opportunity to give priority to common goals over personal expectations.

The article continues by describing the architectural program and how the initial base narrative was materialized into the project, concluding with a reflection on the importance of the presented design-tools in keeping the team focused on common results.

\section{Context}

The project takes place in a building that dates to the second half of nineteenthcentury, located on Ferreira Borges street, $n^{\circ} 135$ to 139, in the city of Coimbra in Portugal. This edifice is one of several buildings that are part of the historic center of the city. Its original format was composed by commerce on the ground floor, and residences from the $1^{\text {st }}$ to the $5^{\text {th }}$ floor, having been the $4^{\text {th }}$ and $5^{\text {th }}$ floor added subsequently to the original construction, and of which there weren't any official records in the city hall. Due to several interventions undergone over time, often taking place without proper monitoring, the building was losing some of its original characteristics, especially regarding its main facade and exterior windows. At the initial point of intervention, it was at high risk of collapsing, as are many other buildings in the surroundings. It also presented serious structural problems and pathologies associated with abandonment, mainly caused by infiltrations resulting from the degradation of the roof and the external windows, revealing the need for an urgent intervention.

1Estudioama based in Aveiro is a product and interior design studio, founded in 2003 by 2 partners (Pedro Bandeira Maia and Raul Pinto). 
It is important to note that the building is integrated into an area of the city with archaeological importance and is considered a real-estate with relevant cultural and historical heritage. Moreover, it is linked to the application of the University of Coimbra to become a UNESCO World Heritage Site. (fig. 1)
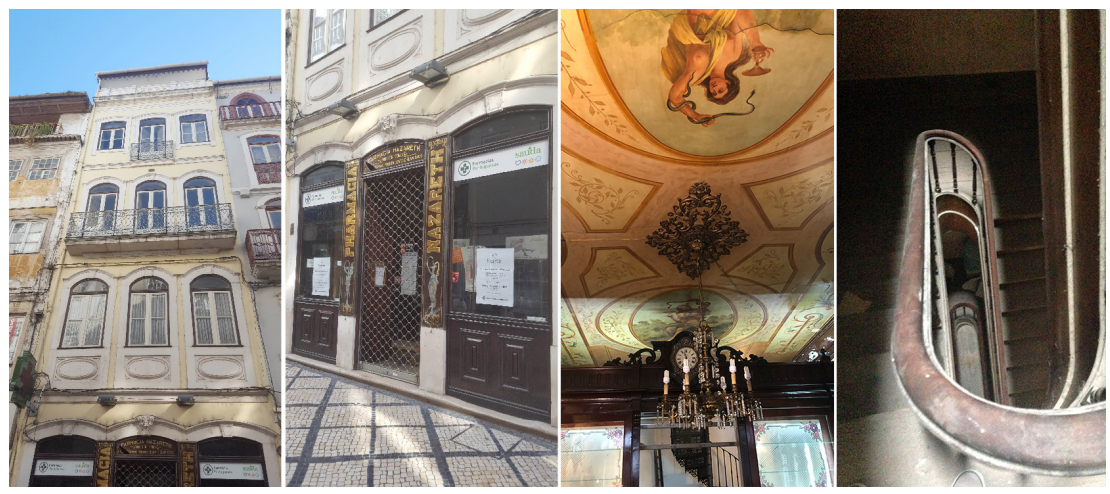

\section{Team}

The project was developed, from the beginning, by a team with different expertise that had never worked together. The disciplines of interior and product design were supervised by Estudioama, architecture and engineering by the architect Cátia Fernandes, graphic design by Estudioama and Aleksandra Kosztyła, archeology by Luís Fernandes, and in a final stage conservation and restoration by Raquel Misarela.

In this document, we will put emphasis essentially on the interior design process and on the tools implemented to manage the project from the concept to the final outcome. We will also intend to explain how design worked as a mediator between the requirements of each area of expertise and the common goal, by keeping a homogeneous design language, handling personal interests, and managing expectations.

[Fig. 1]

From left to the right: facade of the building; main entrance; interior furniture of the ground floor; main staircase.

(c) Arch. Cátia Fernandes, 2018. 


\section{User expectation as the program for the design brief}

The project brief is the result of the intended user experiences discussed by the client, architect and the design team in the preparatory meetings.

As an overview, the architectural program proposed a spatial reorganization to provide the building with the requirements and characteristics necessary to function as a guesthouse. The ground floor, where previously was located a pharmacy, and the upper floors, where were several housing apartments, were to be transformed into a single guesthouse with a common language. The program intended to transform the ground floor into a reception area and the top 5 floors into 7 suites and 2 dormitories, respecting and valuing the existing structure and elements, as well as recovering a part of the original decorative elements.

Specifically, and within the scope of the interior design project, the reorganization and spatial qualification (interior compartmentalization) were programmed to maintain the existing high ceilings, furniture, staircases, and fresco paintings. The only deep structural intervention was imposed on the attic, which until now functioned only as a storehouse. This top floor was redefined by adding skylight to guarantee sufficient light to the future room, and by extracting part of the existing roof to make a terrace that aimed to be a chillout point with the view of the city of Coimbra.

The defined program had in its core the recovery of the main staircase that worked as the soul of the building, connecting the $1^{\text {st }}$ to the $5^{\text {th }}$ floor. The connection from the ground floor to the $1^{\text {st }}$ floor was made by an old spiral cast-iron staircase, that did not fulfill the safety requirements in the legislation, and for that reason the intention was to recover it just as a decorative element that preserves its original language, integrating it in the interior design language.

After several meetings of the client and the design team, the final program defined the ground floor as a reception area with a small lounge and a bar open to the public, and a second space that would work as a distribution area with the access to the stairs and elevator. The latter includes a small support kitchen, and works also as a small private lounge for the guests.

The rooms situated on $1^{\text {st }}$ to $5^{\text {th }}$ floor and facing the main façade should be suites with a distinctive language, but without excessive luxury. The rooms facing the interior façade, that overlooks an interior courtyard, were to be transformed: the 1st and 2nd floors into dormitories, with at least 3 single beds; and on the remaining 3rd, 4th, and 5th floor into suites with an informal and relaxed language. Within the scope of the outdoor spaces it was planned to requalify the light vent into a patio, as well as to open the roof of the $6^{\text {th }}$ floor into a terrace.

The general aesthetic approach was to introduce contemporaneity to the existing space, valuing the building's past and respecting its history, identity, and memory. 


\section{Design as a mediator}

The "Design Dictionary: Perspectives on Design Terminology"2 starts the definition of design by stating that it is "impossible to offer a single and authoritative definition". Thus, it is common sense that "design is intrinsic to human behavior" and that it is an "attitude to understand the everyday, to anticipate and react on it" 3 . Alice Rawsthorn explains that every change that humans impose on themselves or on their surroundings is an act of design, but that this is done instinctively ${ }^{4}$, indicating that design pre-exists the word (as do most things), and, more importantly, the profession. Victor Papanek reinforces the idea that design is basic to all human activity, from "composing an epic poem" to "baking an apple pie" or "educating a child", adding that it is not only about "conscious [acts but also any] intuitive effort to impose meaningful order"5. If design is correlated to the process of how humans yield change, and if humans are evolving cultural beings, the way we perceive and instigate change, and consequently, how we design and understand design is an evolving cultural concept too.

This mindset brought forward the idea that all the stakeholders involved in imposing change onto the existing building should be considered as valid active voices in the design process. Client, contractor, architect, graphic and interior designers were integrated as active elements of the design team, and this generated the need to coordinate and manage both professional and non-professional "change enforcers" into the design process. In this case design can be perceived on different levels: as a professional form giving activity that mediates between matter and form, as a team leader by overseeing the project coordination, and as a facilitator between stakeholders. We consider this approach to be design-led, seeing that it keeps the consumers' expectations and behaviors as the focus guideline for the design team and uses design tools such as Customer Journey Map, Personas and Image Boards to generate a common language and goals.

When problems are very hard to formulate, generate open solutions and need a holistic approach to be tackled, they are normally referred to as "wicked problems"'. Cross-functional collaboration teams that grapple these problems by viewing them as something integrated in a complex system instead of something on its own, tend to be more successful and the outcomes generally lead to a more multidimensional approach. To understand the complexity of a "wicked problem", its interacting and intertwined processual events, a system should not be dissected

2 Erlhoff, Michael and Marshall, Tim. Design Dictionnary: Perspetives on Design Terminology (Berlim: Birkhäuser, 2008 ), 102. 3 Boelen, Jan and Sacchetti, Vera. Designing Everyday Life (Zürich: MAO,Ljubljana and Park Books, 2014 ), 19. 4 Rawsthorn, Alice. Hello World: Where Design Meets Life (London: Penguin Books, 2013).

5 Papanek, Victor. Design for the Real World: Human Ecology and Social Change (Chicago: Thames \& Hudson, 1985).

6 Rittel, H. W., \& Webber, M. M. (1973). Dilemmas in a general theory of planning. Policy Sciences (4), pp. 155-169. doi: https://doi.org/10.1007/BF01405730 
but be given a valid solution, in the same way as a random phrase of a book should not be expected to grasp the whole narrative. The system must be seen as broadly as possible, and in most of the cases the solution resides in the shifting of the system from one state to another.

"Design thinking"'7 is commonly referred to as a creative form of complex problem solving within cross-functional teams where collaboration between many fields of expertise is considered as a key factor. In this context, designers' ability to facilitate and mediate is core to a successful outcome $^{8}$. In this case design facilitates the communication in the ambient where you can find barriers that derive from specific terminologies and language styles and helps to respect personal goals within a common goal, raised as the main concerns for the designers as project leaders.

Cross-functional collaboration can be approached in many forms, depending on the alternative ways of interaction between disciplines. Multidisciplinary, transdisciplinary, and interdisciplinarity are referred to as forms of knowing, acting, and thinking ${ }^{9}$.Multidisciplinary denotes coming together of different disciplines, while transdisciplinary refers to deep integration of the different disciplines into one, and interdisciplinarity is considered the term to represent the problem solving through close collaboration between more than one discipline ${ }^{10}$.

\subsection{The importance of interdisciplinarity?}

Paulo Parra"mentions that the areas of Human Body Sciences, Natural Sciences, Material Sciences, but also Human Sciences produce knowledge that, crossed with design, allows to build the project culture at the service of humans and their quality of life, in harmony with the environment in which they live. This vision, centered on the sharing of concepts and knowledge, promotes different angles of observation and enhances the quality of the design project, as well as the development of new and different solutions that can promote a multi-experience that is physical/material/tangible but also sensorial/immaterial/intangible.

In the development of interior design it is presented as essential to promote close interactions within the different areas that contribute to the final project, but also, whenever possible, to cross areas that traditionally are not directly related, but that can add creativity and innovation, promoting the project's ability to "tell an unexpected story" and avoiding a common vision of

7 Brown, T. (2008). Design Thinking. Design Issues, 2, pp. 5-21.

8 Sanders, E. B.-N., \&Stappers, P. J. (March de 2008). Co-creation and the New Landscapes of Design. Codesign, 1, pp. 5-18. 9 Bordkar, P. (2000). Design as Problem-Solving. Em R. Frodeman, \& J. T. Klein (Edits.), The Oxford Handbook of Interdisciplinarity (pp. 273-287). Oxford: Oxford University Press.

10 Dykes, T., Rodgers, P., \& Smyth, M. (June de 2009). Towards a New Disciplinary Framework for Contemporary Creative Design. CoDesign, 5, pp. 99-116.

11 Parra, Paulo. Design Simbiótico: Cultura Projectual, Sistemas Biológicos e Sistemas Tecnológicos (Tese de Doutoramento, Universidade de Lisboa, Faculdade de Belas Artes, 2007). 
spaces and objects. More specific fields of design compete for this purpose, such as interaction, experience, emotion, and behavior design, that result from different areas of the cognitive sciences, being subsequently reinterpreted under the lens of design and transported to the design ecosystem. In this sense, interdisciplinarity in design can generate new approaches to the existing or future challenges by enhancing divergent thinking. De Bono ${ }^{12}$ refers to this strategy as "Lateral Thinking", arguing that creativity and innovation are excellent tools for progress, suggesting the need to look for alternative paths that enhance responses from the obvious methods of thinking. It is in this context that interdisciplinarity moves, giving identity to the project, since it comes from the characteristics, perspectives, territories of knowledge, and experiences of each of the contributory areas that, combined, end up producing a differentiated project vision contributing for "(...) connecting the unconnected in unusual ways (...)"13.

In this project the intention was to promote this collaborative approach, intersecting personal contributions from each stakeholder into a single unified design proposal, and to see design as a mediator between disciplines as will be described further on in the document.

\subsection{Design tools}

The customer journey map - defining and mapping the future customer's experiences - is a core to the success of a business that is dependent on how each customer communicates their personal experiences to others on accommodation-booking digital platforms. This tool proved its importance by building a common mindset for the design team - the guesthouse should offer different experiences for different clients, and the pre-existing pharmacy should be reflected visually and emotionally in each space differently. Furthermore, the rooms were not to be perceived as mere accommodations, but as personalized sleeping prescriptions ${ }^{14}$.

Personas - were generated to consolidate the customer journey map (or maps). "Each map should represent a journey specific to a persona"'15, in this case 3 Personas were generated based on the cities' tourist's records: $1^{\text {st }}$ - the small groups of young travelers that is city hopping, looking for cultural and social interactions towards intense experiences; $2^{\text {nd }}$ - the romantic couples focused on each other, seizing intimate moments; and $3^{\text {rd }}$ - the globetrotters, traveling alone or in pairs, exploring local cultural peculiarities. For each of these three personas, a Journey Map was planned, from the moment of their arrival at the guesthouse, passing through their check-in process, and how each room would be attributed to them based on

12 De Bono, Edward. Lateral Thinking: A Textbook of Creativity. (Penguin Books, 2009).

13 Woolley-Barker, Tamsin. Teeming: How superorganisms work to build infinite wealth in a finite world (Ashland, Oregon: White Cloud Press, 2017), 154.

14 Martin, Bella and Hanington, Bruce. Universal Methods of Design (Beverly, MA: Rockport Publishers, 2012).

15 lbid, 197 
their sleeping habits and/or disorders. Like in a pharmacy, prescriptions are attributed based on one's personal symptoms. Some rooms have calming ambiences and an infusion known for its relaxing properties would be waiting for them, and its smell would invade the room, while others have soothing sounds and placebo sleeping tablets made of candy. Each persona helped to grasp a set of goals, expectations, tasks, and key interactive moments.

Image boards - multimedia mood boards using collages and drawings were created for the design team to define different ambiences for all personas' accommodations, without losing the overall general concepts and aesthetics. Image boards worked as an internal tool that allowed all stakeholders to gain a tangible grasp of the intended design. During the construction process it worked as a visual reminder, keeping focus even when unexpected events occurred. This tool worked also as an element of client engagement, allowing him to actively participate in the decision making beforehand, lowering the possibility of disappointments and last-minute changes $^{16}$.

"Open" Double Diamond - for the building that is located in a site considered by the city municipality as historical and cultural interest, the traditional way of approaching a design methodology, where one is guided through a set of steps from challenge to outcome, was not seen as a valid approach. The building itself was an organic element that was still to be fully understood and the project would be under the subjective analysis of the city planning department inspectors. Instead of the traditional one, an open strategy was put in place, where the process leads from challenge to a scenario for possible outcomes, instead of just one fixed. This strategy proved to be beneficial not only because it minimized frustrations (seeing that the project was not focused on a fix goal, but on an array of possibilities), but also gave the design team an opportunity to react to the building's idiosyncrasies. Image boards were useful to build the scenarios and kept changes in context. Keeping the four stages of the Double Diamond methodology - Discover, Define, Develop and Deliver - where Discover and Develop are divergent thinking moments and Define and Deliver are convergent acting moments. In this project, Deliver was also kept as open as possible. The main goal of not converging the Deliver stage to one closed outcome is based on the idea that user feedback will be seen as a tool to constantly update the experiences ${ }^{17}$.

\subsection{An elastic mindset as a binding tool between actors and contexts}

Now, more than ever, the bulk of the material world's "form giving process" is the result of a multidisciplinary collaboration, where design has an important role and is seen as an independent discipline. It contributes to a better understanding of the relation between pre-conceived ideas and a final form. 
Design is "mediation between different spheres", that occurs between areas of knowledge, "it is concerned with style and utility, material artifacts and human desires, the realms of the ideological, the political and the economic, [...] it serves the most idealistic and utopian goals and the most negative, destructive impulses of humankind", therefore it can be metaphorically described as "a discursive practice" that results in material and immaterial artifacts that are a metalanguage of human behavior" ${ }^{18}$. Being "an expression of purpose ${ }^{19}$, when design is "isolated from people and the everyday environment, [...] the designed object becomes a fetish"20. The designer, in this sense, is and will always be a coauthor of the material world's form giving process, may it be by dialoging with other areas of expertise, technological apparatus, organic spontaneity or the transcendental.

Keeping an elastic mindset, and by elastic we mean the ability to resume original shape after stretching or compressing, designers can stretch out into different areas of expertise, they can easily empathize with different "Personas" and situations, forecast the material and immaterial implications of a certain decision, and still keep the ability to compress back into the original brief. In this project, design is positioned as a mediator between different languages of each specific area of expertise by looking for common grounds between them, and by extracting unique points of view into the pre-established aesthetic language. In this situation design acts as a facilitator between the existing building and the client's expectations, by constantly giving a visual dimension (through sketching and rendering) that allowed the client to understand the implications of the different solutions to a given problem. It also replaced a fixed-ended conceptual narrative with an open narrative that helped manage expectations without exceeding the initially set budget.

\subsection{Designer as mediator between matter and form}

Design, in its traditional role, embodies ideas through matter, "and designed objects are [constantly] redefined through new understandings of the relationship between the material and immaterial aspects of design"21. Being a material, "the matter from which a thing is or can be made; [the] physical substance in general, as distinct from mind and spirit"'22, means that the uncovering of new materials or new ways to conform and inform the existing ones, will result in new ways of making things. Design, as Klaus Krippendorff writes in The Semantic Turn: a new foundation for design advertises, is not just about making things but fundamentally about

18 Walker, John. Design History and the History of Design (London: Pluto Press, 1990), 09-14

19 Eames, Charles. 1972. "Design Q \& A". (Youtube, 05:29. https://www.youtube.com/watch?v=bmgxDCujTUw) 20 Walker, John. Design History and the History of Design (London: Pluto Press, 1990), 58.

21 Caccavale, Elio, and Shakespeare, Tom. Thinking Differently about life:Design, Biomedicine, and "negative capability", 2014. In Yelavich, Susan andAdams, Barbara. Design as Future-Making (New York: Bloomsbury Academic,2014).

22 Oxford University. (s.d.). Definition of Material in English (Accessed September 2, 2018.

https://www.lexico.com/en/definition/material). 
"making sense of things, [...] the products of design are to be understandable to their users"23, thus design is not only required to apply new materials, but is essentially compelled to mediate materials into meaningful comprehensible artifacts.

Going into the origins of the word matter, we arrive at the Latin mater (mother) ${ }^{24}$, suggesting that matter perceives and "generates" the materials and the forms to come, and that in some sense the (mother) matter itself influences the final form. This idea is an old one, the sculptor Michelangelo Buonarotti stated that "every block of stone has a statue inside it, and it is the task of the sculptor to discover it. I saw the angel in the marble and carved until I set him free" 25 . This sustains the idea that matter influences the outcome even before it exists, this might be through its physical characteristics or through the author's subjective interpretation of what that specific matter wants to be.

"Everything is made from something" and not only does "the material itself convey messages, metaphorical and otherwise, about the objects and their place in a culture" but also is a reflection of sociocultural and economical aspects that drive one material forward in detriment to others ${ }^{26}$.

The intervened building was looked upon not as a decaying vessel to be hollowed out, but rather as a baseline for the construction of a narrative that focuses on its ethos by bringing to evidence its intangible qualities. The existing architectural and structural elements were seen as important as the details that remained from its previous functions. The multicompartment furniture with its array of glass jars, the fresco on the ceiling, the spiral cast iron staircase, and the inner courtyards, are examples of elements that are embedded in the story of what the building was and should keep being. Design became a mediator between matter and form.Color and light were the main instruments to translate the existing characteristics into the new program. Blending the new with the old was achieved by focusing or dimming light upon specific details, and also by using blocks of bright colors to overlap the existing pastel ambiance. Some constraints were imposed onto the design team by the city municipalities' planning department inspectors. The cast iron staircase did not fulfill the safety requirements imposed by today's regulations and had to be removed for the municipality to approve its fire escape plan. The staircase, having been identified as a core symbolic and aesthetic element, was not removed physically but rather functionally. With minor interventions, it became a structural element to the new staircase that was built to satisfy the needed requirements. The overlapping staircases are representative of how design combined old and new languages and materials into a new dialect that became the conducting wire that adapted the existing requirements to the new ones.

23 Krippendorff, Klaus. The Semantic Turn: A New Foundation for Design (New York: Taylor \& Francis Group, 2006$), 16$.

24 Oxford University. (s.d.). Definition of MATTER in English (Accessed December 8, 2017.

https://www.lexico.com/en/definition/matter).

25 Parker, Nils. 2013. The Angel in the Marble: Modern Life Lessons from History's Greatest Sculptor (Accessed January 12, 2018. https://medium.com/@nilsaparker/the-angel-in-the-marble-f7aa43f333dc).

26 Freidel, Robert. Some Matters of Substance. 1993. In Lubar, Steven and Kingery, William. History from Things: Essays on Material Culture (Washington: Smithsonian Institute, 1995, 41-50), 42 
Humans have a perceptual experience of what matter is, and this perception is limited to a very specific scale and context. One can say that matter is revealed to us through the constant interactions that occur between the matter which defines our physicality and everything else, and that our comprehension of it is limited to our brain's ability to process the information that is sent to it by our senses (our physiological ability to provide data by stimulus) ${ }^{27}$. This also signifies that most matter can be mediated into being perceived in one way or another. In this practical case, we believe that by looking at the raw matterto be worked on empowered the design team to see beyond the building as one functional artifact. Instead it was approached as an amalgam of elements to be emphasized, trivialized, or repurposed as one. The term "amalgam" looks to suit the design approach, seeing that it did not only combine the existing with the new but in this case intertwined both into one single artifact that, somehow, lost their time-related barriers. As it is the case of some fresco paintings that dilute into the new inbuilt ceiling.

\section{Project - the Soporific guesthouse}

\subsection{The importance of building a narrative in interior design}

Sikes and Gale ${ }^{28}$ describe human beings as storytelling creatures, who perceive the world and things through the construction of narratives to explain and interpret events both for themselves and for others. In this sense, the narrative takes humans to extrapolate beyond reality, makes them dream or enchant through a universe of ideas, images, visions, offering an alternative path to the "raw" and immediate reality. This imaginative capacity is the quest to tell a story, which gives meaning to the inexplicable, to what does not exist yet, is nothing more than an attempt by man, as Sartre ${ }^{29}$ claimed, to create a world that is not of this world.

We must, however, consider that, despite the ethereal character of metaphor and poetics, they decisively influence design of alternative universes, with an impact on human behavior, contributing to the intersection of the dimension of experience, emotion, and behavior with the design.

Regarding the application of the narrative in design, Erickson ${ }^{30}$ argues that the stories provide a good first step in what is important, from the users' point of view, allowing the designer to understand their context and, therefore, providing the premises for further exploration. Erlhoff

27 Pfaffmann, Carl. 2017. Human sensory reception (Accessed 22 July, 2019.

https://www.britannica.com/science/human-sensory-reception).

28Sikes, Pat and Gale, Ken. Narrative Approaches to Education Research, Faculty of Education, University of Plymouth, 2006. In Tully, Robert. "Narrative Imagination: a Design Imperative," Irish Journal of Academic Practice: Vol. 1: Iss. 1, Article 8, 2012.

29 Sartre, Jean Paul. The Psychology of Imagination, L'imaginaire: Psychologie phenomenologique de l'imagination, Gallimard, 1940, translation published as The Psychology of Imagination, Philosophical Library, 1948. Accessed May 15, 2020 from: http://plato.stanford.edu/entries/sartre.

30 Erickson, Thomas. Design as storytelling (Interactions, 1996). 
\& Marshall ${ }^{31}$ identify the open incorporation of the narrative as a characteristic of contemporary interior design, evident in several commercial thematic spaces where it is increasingly common, a fun and less linear approach to the narrative, giving as an example the project of two stores in Akita, Japan, AZB - x-Compiler and X-Assembler - that reference Japanese toys and robots. They also consider that the narratives can be extracted not only from cultural icons but also from the design typologies themselves, such as the Claska Hotel in Tokyo, where the project is based on the cutting of silhouettes of appliances on the walls of the hotel rooms.

In this way, the narrative applies to the design of spaces where language, as Tversky and Lee $^{32} \mathrm{claim}$, provides a systematic descriptive structure of the space, conveying its idea. Given that, a space is schematized similarly in language and cognition. In this sense, the power of language itself, as a tool to build the imagined space, should not be underestimated.

According to the aforementioned, it became imperative to design an elastic narrative, that would conceptually guide the project, provide an explanation, and spread a seductive discourse of the options taken, promoting, simultaneously, the involvement of the client. It is from that moment that meaning emerges.

The building is marked by the ground floor space that in recent decades has been a well-known pharmacy in the city, both for its iconic interior with wood furniture and wall covering, and for a richly fresco painted ceiling, that makes an immediate flashback connection to the history of the space. The exploration of the building, when still vacant, revealed the existence of an array of visual and material references abandoned by the former owners, such as pharmaceutical labeled bottles, compendiums, or different instruments for medicine making. Realizing the potential of this material, the design team decided that it should be incorporated into the project's narrative. (fig. 2)

In this way the space, which exuded identity and memory, led to the exploration of the pharmaceutical imagery of ancient recipes, the meticulous manipulation of substances, their colors and shapes, or the use of the ancestral knowledge related to the natural substances. It was intended to preserve the history of the place in a dialogue with the language and the design requirements that, in essence, are linked to the pharmacological universe of substances of wellbeing, rest or relaxation.

31 Erlhoff, Michael and Marshall, Tim. Design Dictionnary: Perspetives on Design Terminology (Berlim: Birkhäuser, 2008).

32 Tversky, Barbara and Lee, Paul. 1998. How Space Structures Language (accessed 5 June, 2020. https://www.

researchgate.net/publication/221104021_How_Space_Structures_Language) 


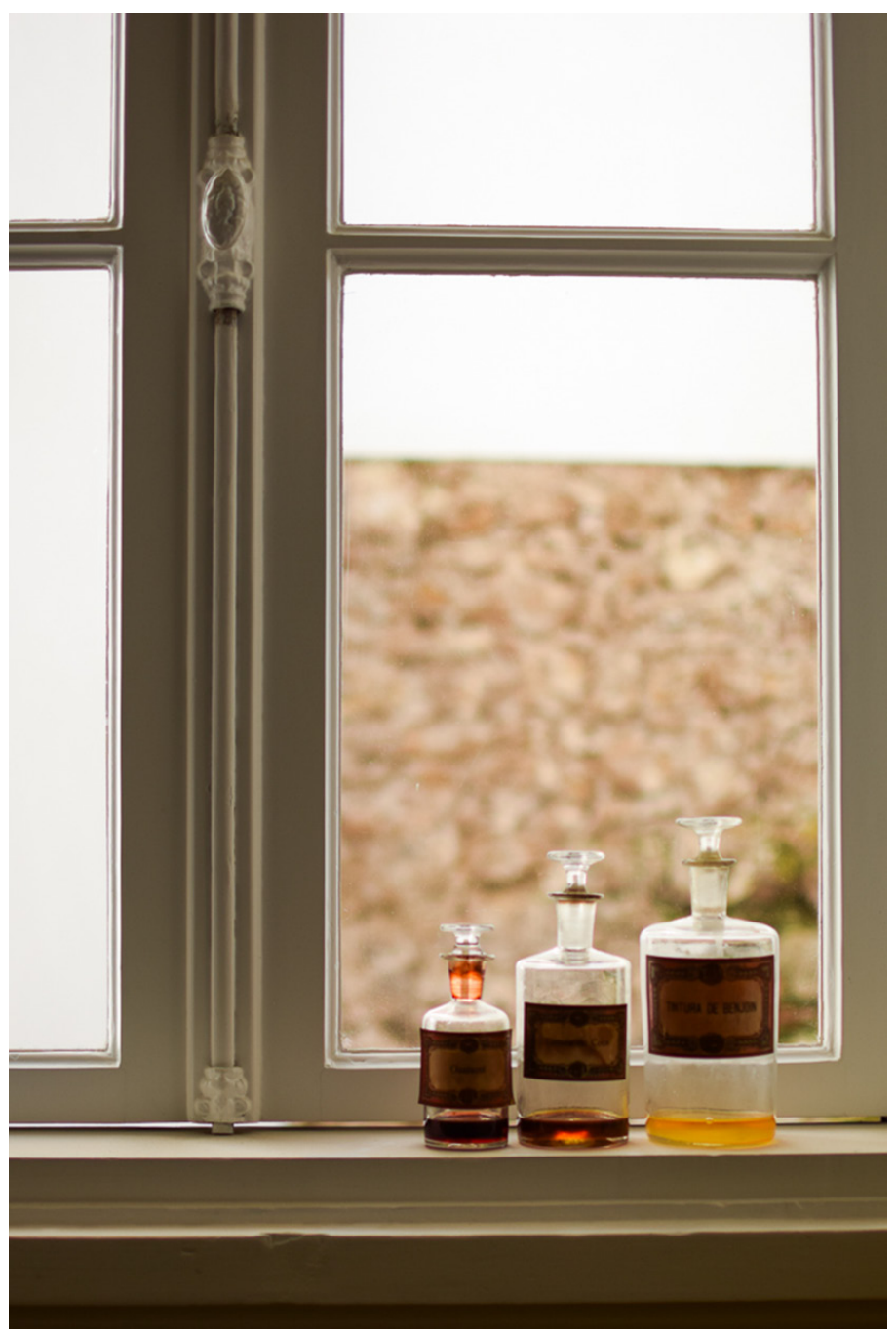




\subsection{Phase 1 - Project narrative}

This phase of interaction with the client corresponded to the presentation of the proposed narrative for the development of the project that would fuse the client's imagination and bring together the ideas and premises of the future works, justifying the design options throughout the process. The basis for the construction of the narrative was the need to urgently give a homogeneous meaning to the interventions that would be necessary to carry out on all 6 floors, offering rhythm, dynamics, and diversity on each floor, but that simultaneously would found points of contact between all, to offer a coherent final result. (fig. 3)

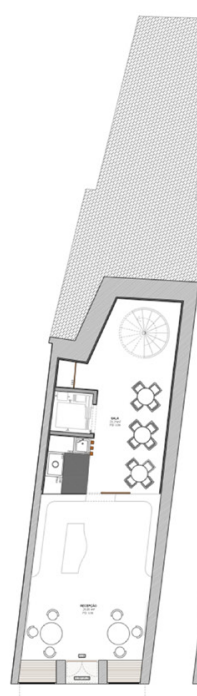

PLANTA Re ReS DO CHä́

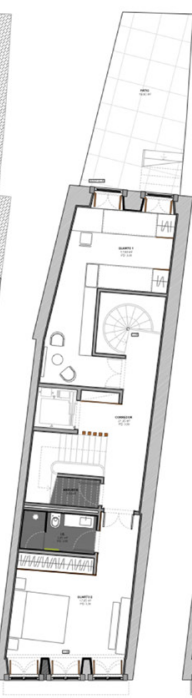

PLATIA DE PSO I

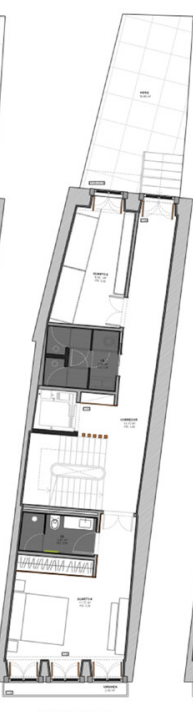

PLANTA DEPSO 2

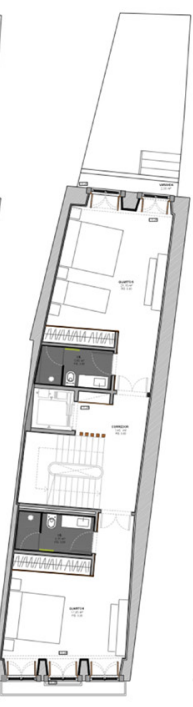

PLANTADE PSO 3

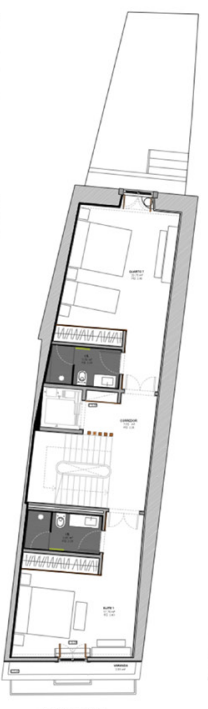

PLANTA DE PSO 4

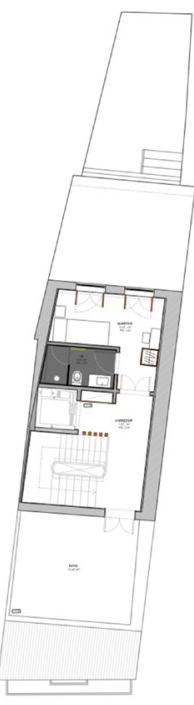

PLANTADE SOTĹO 
With the aim of emphasizing the pharmaceutical history of the building, and taking this as a starting point, we worked keeping in mind that those who arrive (clients) want to relax and have comfort to sleep. Flowers with soporific properties, such as poppy, bell, hops, valerian, and chamomile, were defined in each floor as an conceptual image reference that would "induce sleep". Meanwhile it was defined that the common areas of each floor would be neutral, the predominant colors of each soporific plant would provide the chromatic reference for the rooms, as well as offer numerous visual options for its decorative elements (furniture, textiles, coverings, graphic compositions). They also showed potential to contribute to the definition of the elements that would inhabit each room, since the project goal is to potentiate experiences of the clients, contributing to the development of the sensory aspects of each room (soaps, sweets, flowers, etc.). (fig. 4)

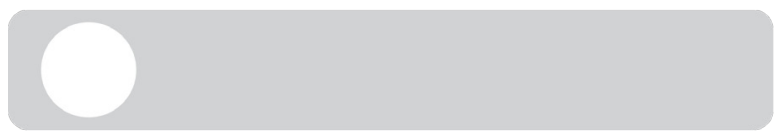

Piso 0

Receção + Concept Store Zona de refeições/estar
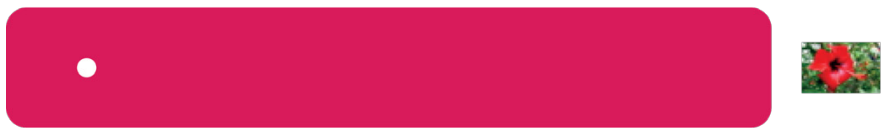

Piso 1 - Papoila

Quarto Xarope Camarata Cápsula

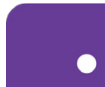

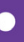
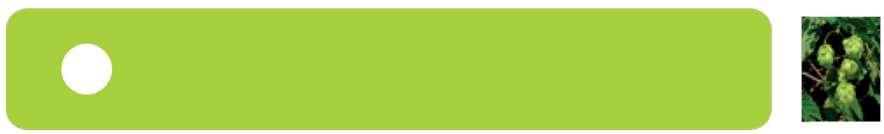

Piso 3 - Lúpulo

Quarto Pó

Quarto Extrato
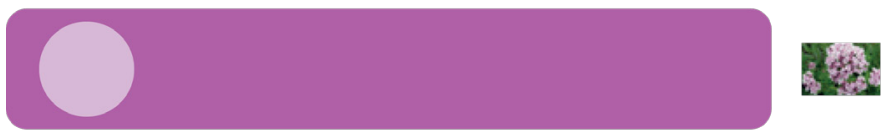

Piso 4 - Valeriana

Quarto Emulsão

Quarto Loção
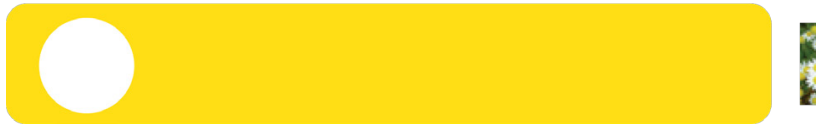

Piso 5 - Camomila

Quarto Tintura

Rooftop Botiga

[Fig. 4]

Diagram with soporific plants, colors and room name's. 
With regard to the design for the experience, authors like Bill Buxton ${ }^{33}$ or Paola Antonelli34 consider that nowadays more and more experiences are designed, and not mere products or spaces. Nathan Shedroff referred in $2001^{35}$, and it remains true today, that the discipline of design of experiences is so new that its own definition is in flux and can encompass traditional and established disciplines as diverse as theater, storytelling, interior design, architecture, among others. Clarifying the concept, Shedroff ${ }^{36}$ defines experience design as an approach oriented to the creation of successful experiences, and not about mediation of the environment, which includes analysis and design in the three spatial dimensions: time, five common senses and interactivity, to which the value for the client, the personal meaning and the emotional context are added.

In this project, the previously referred customer journey map offers triggers to help create new experiences, introduces costumer to the guesthouse narrative, and tries to build an individual experience, since we all feel, hear, and interpret differently.

In order to differentiate the rooms, names were given, inspired by the different types of medication (effervescent, elixir, capsule, syrup, powder, extract, emulsion, lotion, and tincture), which should "work" in an abstract way (vapors, drops, bubbles, dust, etc.), being free of the evident visual and chromatic references, to leave space for the soporific substances to work.

\subsection{Phase 2 - Project's book}

From the beginning the objective of this project was to value the building and existing decorative elements and to preserve its original design, thus contributing to the appreciation of the. In that thought, the existing flooring in oak and handrails were recovered after the necessary treatments. The existing header, as well as the original footer, were also maintained, after the appropriate restoration.

The second phase corresponded to the materialization of the initial ideas proposed in the narrative and the consequent functional, technical, aesthetic, and decorative decision-making. (fig. 5)

33 Buxton, Bill. Experience Design vs. Interface Design (K. Christensen, Ed.: Rotman Magazine, 2005).

34 Antonelli, Paola. 2007. Paola Antonelli treats Design as Art, TedTalks (Accessed May 15, 2012. http://www.ted.com/ talks/lang/por_br/paola_antonelli_treats_design_as_art. Html).

35 Shedroff, Nathan. Experience design (Indianapolis, Indiana, USA: New Riders, 2001).

36 Ibid 


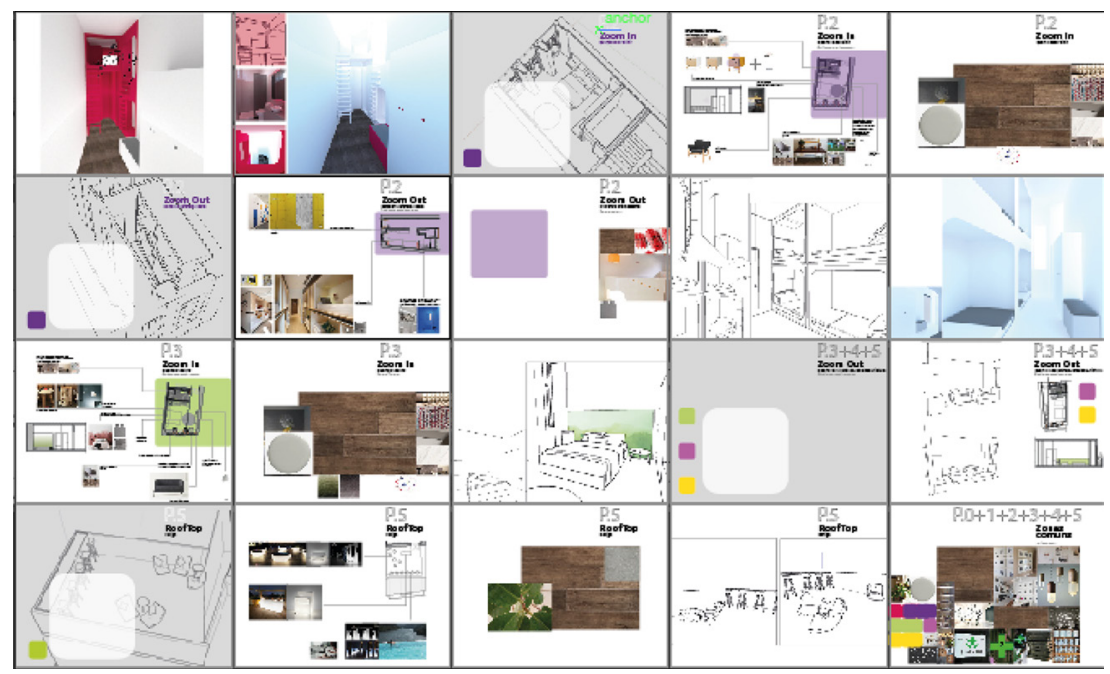

Ground Floor

We intentionally kept the interior of the first ground floor space (reception and lounge-bar) intact by adding only counters in the window areas facing the street, so you can contemplate the dynamics of the downtown while waiting or having a quick drink. (fig. 6)
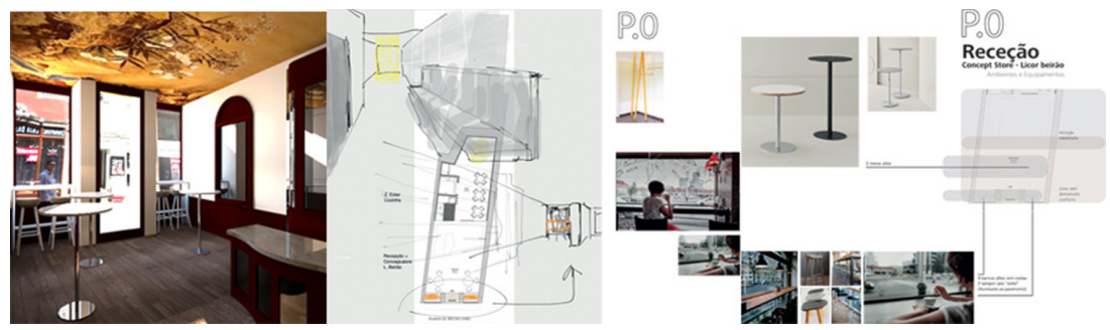

[Fig. 5]

Part of project book
[Fig. 6]

Studies for the Ground floor. 
The second area provides access to the stairs and elevator and includes a small lounge with a kitchen hidden behind a wooden slat. It was decided to introduce vertical elements, lacquered in white, to enhance the wall that supports the new stairway to the 1st floor, also functioning as indirect lighting of the space, eliminating the need of any suspension lamp. (fig. 7)

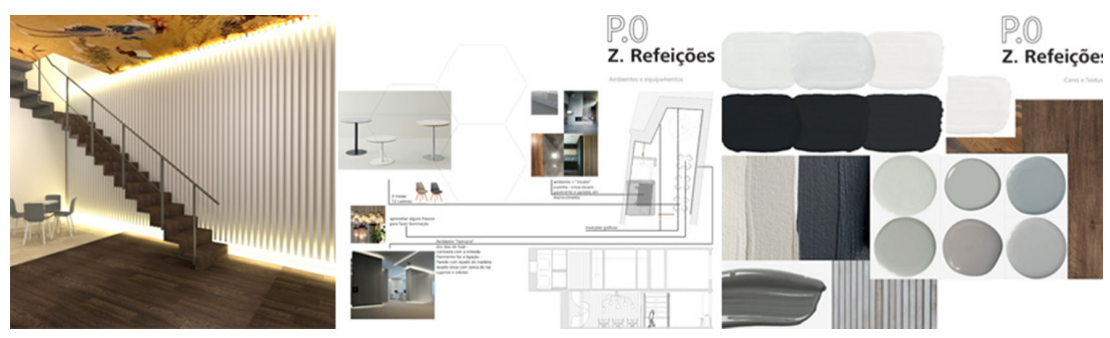

From the design perspective, the ground floor had 3 elements that were the soul of the space and that had to be maintained and enhanced: the fresco ceiling, the entrance furniture, and the iron spiral staircase.

The ceiling of the ground floor is covered with the fresco paintings that represent motifs alluding to the medicine, composed of 2 female figures (goddess Minerva), floral decorative elements, and other elements such as utensils used to produce drugs. Originally painted with oil paint, now it was restored with acrylic, and became the main and iconic element of the entrance space.

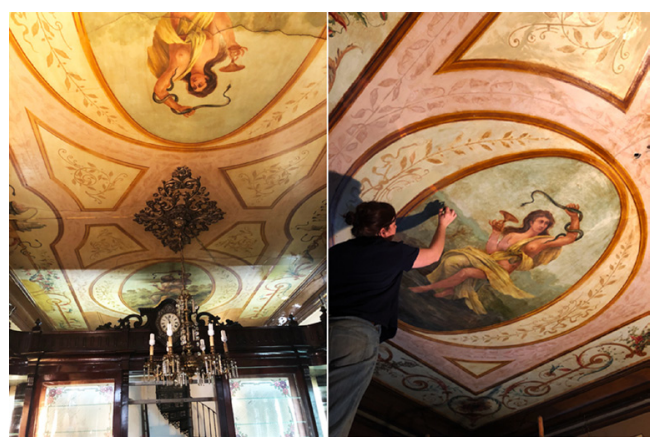

[Fig. 7] 
The furniture, of the same age as the building, was restored and electrified inside the glass doors and on the countertop to continue to function as an exhibition window and to provide ambient lighting. (fig. 8)

The design often had the function of questioning the most immediate solutions and challenging all the parts involved in the project in the search for less obvious and "instant" ones, which happened in the case of the spiral staircase that provides the access to the $1^{\text {st }}$ floor. Contrary to what was originally planned, for technical reasons, this staircase was to be disassembled and placed as a decorative element in the interior patio. As a way to preserve the memory of the space and its aesthetic quality, the design team proposed to keep it in its original location and design a new staircase that, overlapping it, leaves both stair cases to cohabitate, promoting the idea of continuity between the old and the new and guaranteeing functionality. (fig. 9)

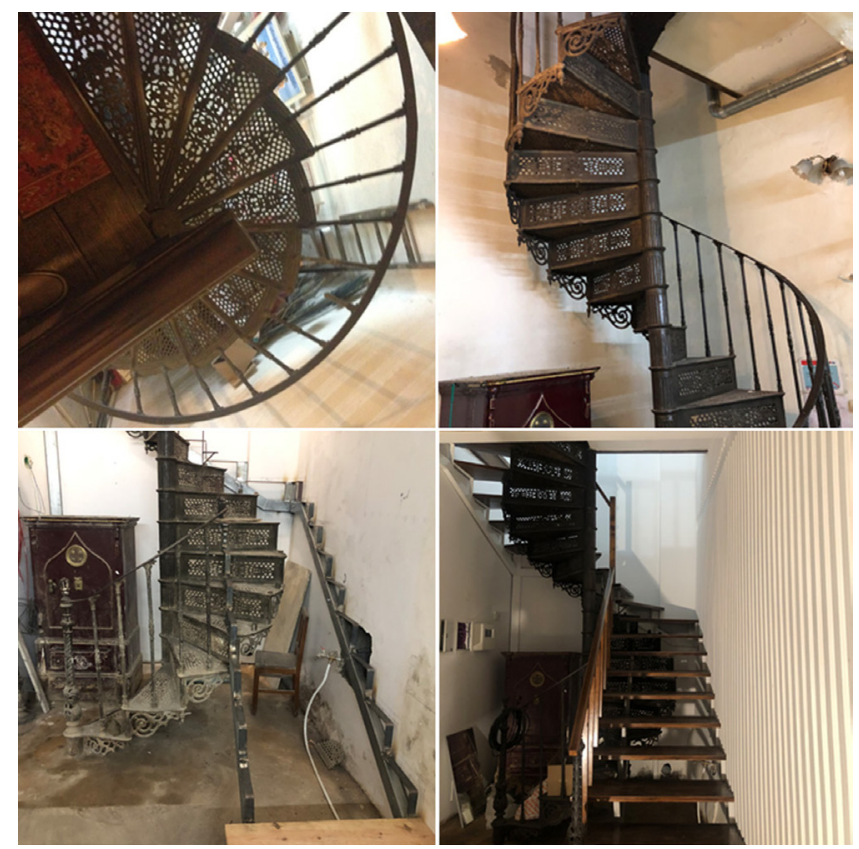

[Fig.9]

Spiral cast-iron staircase and new overlapping staircase.@ Authors, 2020. 
Metaphor in the metaphor: ZOOM IN and ZOOM OUT

In addition to the proposed narrative, two differentiating moments were defined, aiming to find distinguishing points for two rooms on each floor (rooms facing the main street and rooms facing the interior courtyard). (fig. 10)
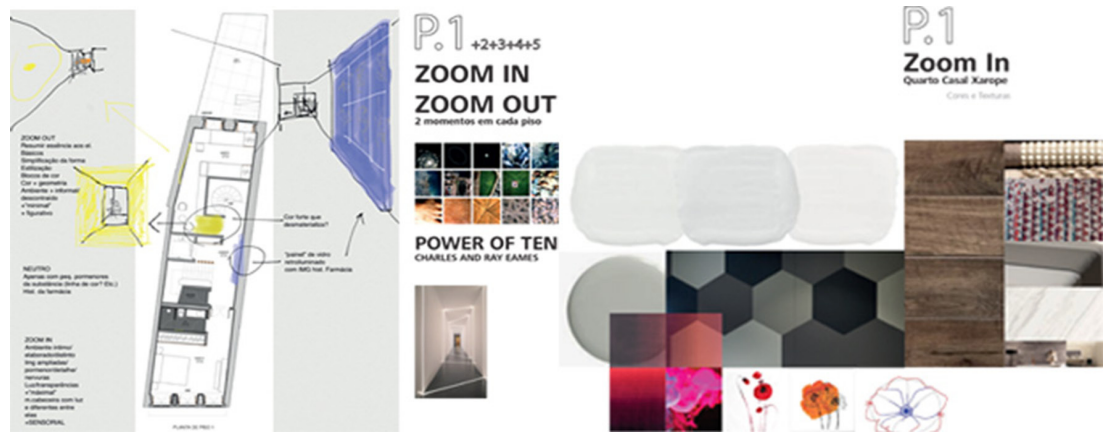

The rooms facing the main street were associated with the concept of Zoom In, which was intended to be more sensorial and detailed, offering an intimate and refined environment, with the premise of working with enlarged and detailed images, in the sense of the "maximal" language where light and transparencies play an essential role. In this situation colour was used in solid blocks reinforcing the idea that you zoomed in too much to see in detail.

The headboard in MDF with upholstery tends to suggest the idea of the molecular structure of the soporific pharmaceutical substances. (fig. 11)
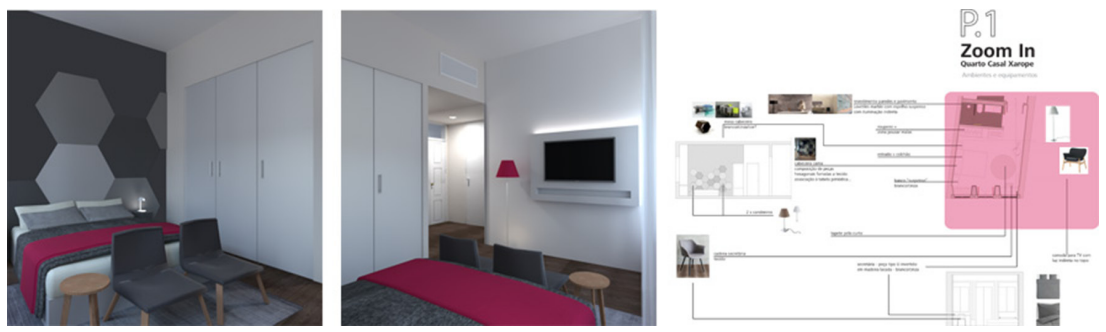

[Fig.10] 
Zoom Out was the concept associated with the rooms facing the interior courtyard, which consisted in adopting simple and stylized language, trying to keep the intervention at an essential level, simplifying the shapes, working with shades, hues and tons of the color that could be dematerialized, creating more informal and relaxed atmosphere. (fig. 12
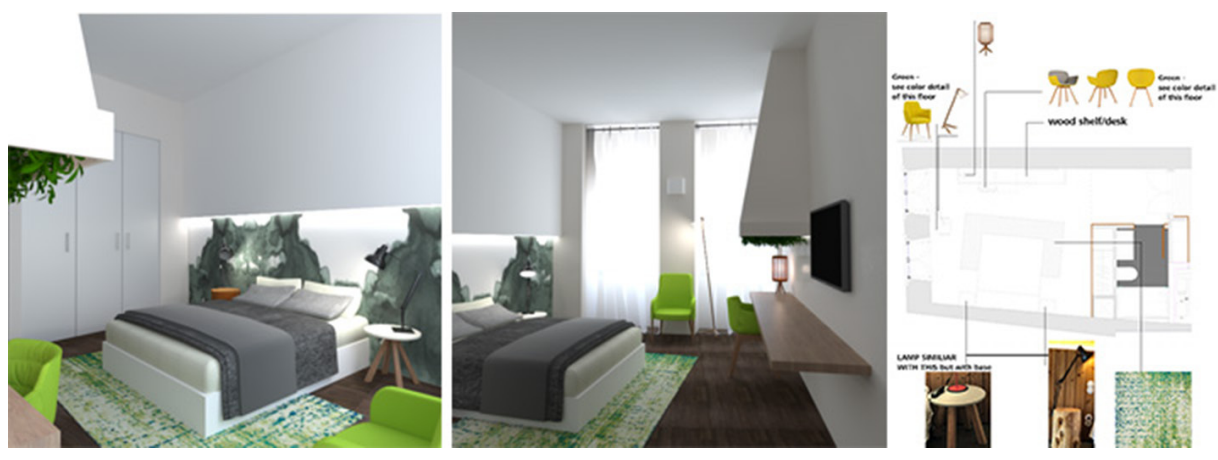

In the bedrooms, as a way to reinforce the created narrative, existing bottles from the old pharmacy were used to develop bedside table lamps. (fig. 13)

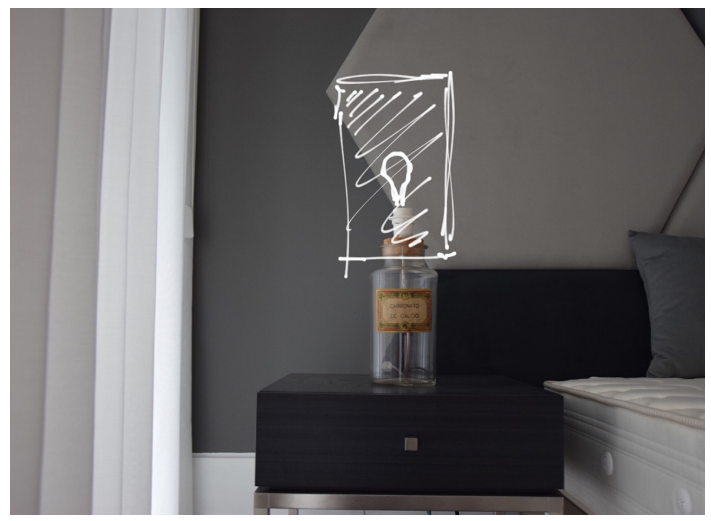

[Fig.12]

Zoom Out room (3rd floor).
[Fig.13]

Studies to adapt pharmaceutical Bottle into bedside table lamp. 


\section{Bunk bed}

As a way to optimize two rooms (on the $1^{\text {st }}$ and $2^{\text {nd }}$ floor, facing the inner courtyard) that did not have enough space to be suites, the design team decided to make them into shared rooms with bunkbeds, seeking to expand the notion of space through blocks of color associated with the soporific plants' palette. (fig.14)
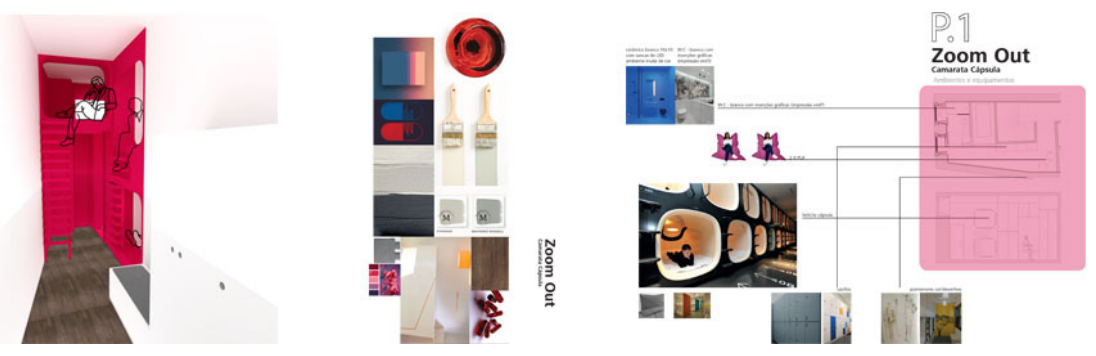

The terrace

In this area the intervention was minimal, consisting in creating a suspended wooden balcony facing the river and the city. (fig.15)

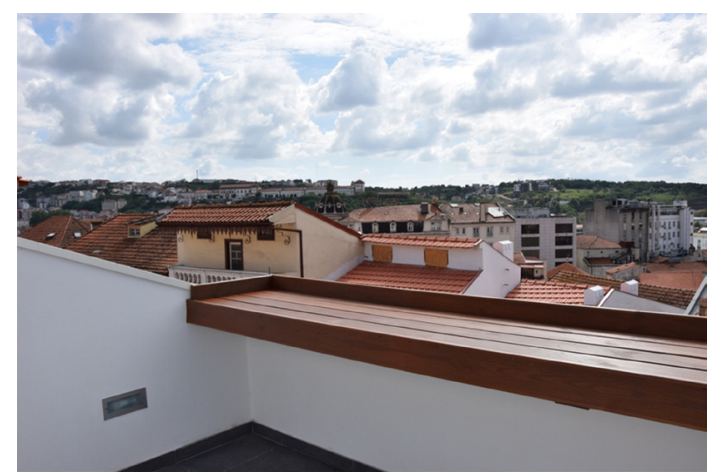




\section{Project Overview}

The following images (Fig. 16) depict some effective achievements of the project so far.
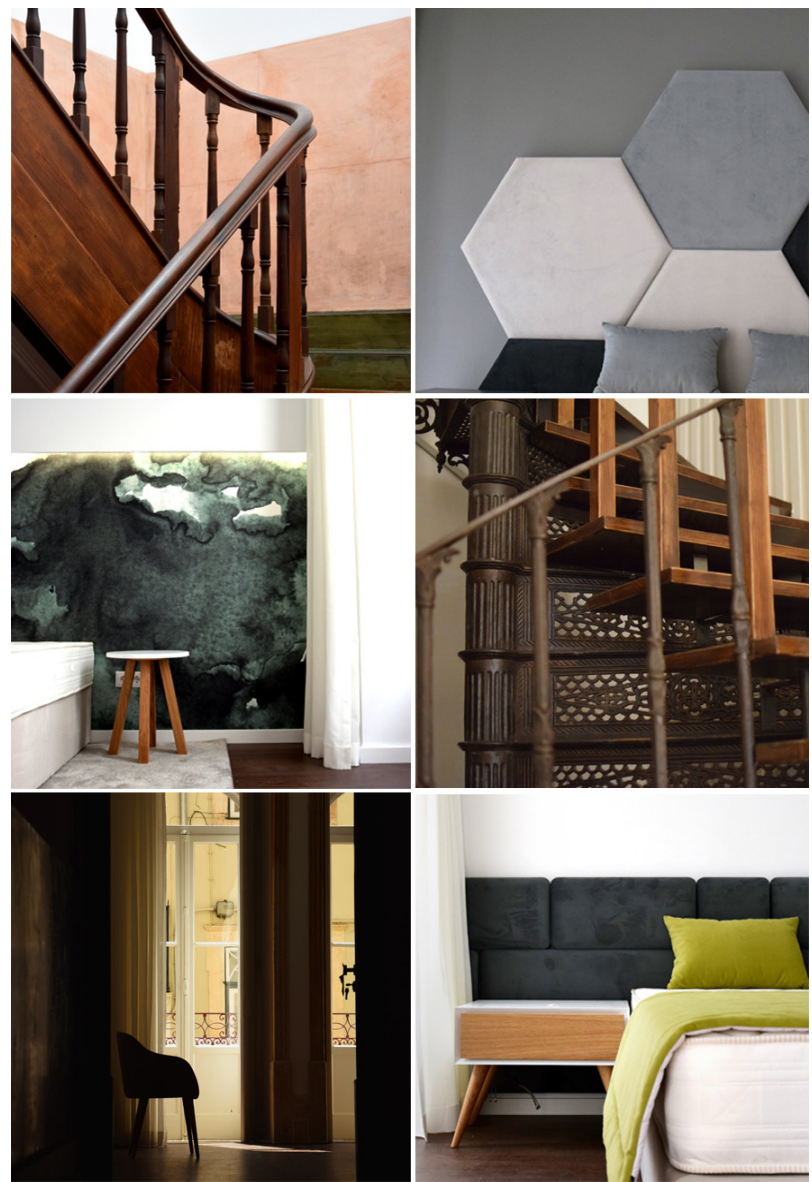

[Fig.16]

Photos of details of the Guesthouse (still under

construction).@Aleksandra Kosztyla, 2020. 


\section{Conclusion}

The displayed interior design project entitled The Soporific Guesthouse is close to completion and will be open to the public soon. We believe that the outcome is a result of the design-led approach that was adopted by the cross-disciplinary design team involved in the process. The design was present throughout all the stages of development of this project, from the definition of the program to the final details of brand identity. This strategy is seen as the main responsible for keeping a homogeneous design language and managing personal expectations of each one involved. It is to stress that design as a problem-solver works as a binder and mediator between all factors.

After the team defined the objectives and generated a guideline narrative, personal interests were analyzed and mediated into the common language through the process. Considering this, we underline the example of intertwining the old and the new staircases into a single artifact that combined functional and aesthetic expectations of each part of the team. The presented design tools defined the procedural approach to the project, and guaranteed that all stakeholders' expectations were safeguarded, and that the key premises were not lost when stumbling into non-perceived aspects of the building.

This article intended to emphasize the importance of the designer's elastic mindset as a binding tool between actors and contexts, valuating different enriching personal contributions and use them as the elements of an integrative whole. We consider that, in this context, the design team not only had the role of the form-giver but also became the mediator between matter and form, the team leader, and the forecaster of the user's emotional experiences. In effect, in a project that is an amalgam of renovation and repurposing and that is rich in historical, decorative, and emotional attributes, metaphors work as storytellers and generate a conversation between spaces and people, resulting in strong emotional experiences. Finally, we underline the importance of generating strong narratives with open outcomes as a core tool in obtaining a common goal that considers the contributions of all stakeholders.

The designer, with a holistic oversight of the project, offers unique advantages when becoming a project leader. 


\section{Bibliography}

Bordkar, P. (2000). Design as Problem-Solving. Em R. Frodeman, \& J. T. Klein (Edits.), The Oxford Handbook of Interdisciplinarity (pp. 273-287). Oxford: Oxford University Press.

British Design Council. (2016). Eleven lessons: managing design in eleven global brands.

Brown, T. (2008). Design Thinking. Design Issues, 2, pp. 5-21.

Caccavale, E., \& Shakespeare, T. (2014). Thinking Differently about life: Design, Biomedicine, and "negative capability". Em S. Yelavich, \& B. Adams, Design as Future-Making. New York: Bloomsbury Academic.

Čelik, M., Boelen, J., \& Sacchetti, V. (2014). Designing Everyday Life. Zürich: MAO, Ljubljana and Park Books.

Charles Eames, R. E. (Realizador). (1972). Design Q \& A [Filme].

Dykes, T., Rodgers, P., \& Smyth, M. (June de 2009). Towards a New Disciplinary Framework for Contemporary Creative Design. CoDesign, 5, pp. 99-116.

Erlhoff, M. (2007). Design Dictionary: Perspectives on Design Terminology. Basel: Birkhäuser .

Freidel, R. (1993). Some Matters of Substance. Em S. Lubar, \& D. W. Kingery, History from Things: Essays on Material Culture (pp. 41-50). Washington: Smithsonian Institute.

Krippendorff, K. (2006). The Semantic Turn: A New Foundation for Design. New York: Taylor \& Francis Group.

Martin, B., \& Hanington, B. (2012). Universal Methods of Design. Beverly, MA: Rockport Publishers.

Oxford University. (s.d.). Definition of Material in English. Obtido em 02 de Set de 2018, de LEXICO powerd by Oxford:

https://www.lexico.com/en/definition/material

Oxford University. (s.d.). Definition of MATTER in English. Obtido em 08 de Dez de 2017, de LEXICO powerd by Oxford:

https://www.lexico.com/en/definition/matter

Papanek, V. (1985). Design for the Real World: Human Ecology and Social Change. Chicago: Thames \& Hudson.

Parker, N. (2013). The Angel in the Marble: Modern Life Lessons from History's Greatest Sculptor. Obtido em 12 de Jan de 2018, de medium.com: https://medium.com/@nilsaparker/the-angel-in-the-marble-f7aa43f333dc

Pfaffmann, C. (17 de Feb de 2017). Human sensory reception. (i. Encyclopædia Britannica, Produtor) Obtido em 22 de Jul de 2019, de Encyclopædia Britannica: https://www.britannica.com/science/human-sensory-reception

Rawsthorn, A. (2013). Hello World: Where Design Meets Life. London: Penguin Books.

Rittel, H. W., \& Webber, M. M. (1973). Dilemmas in a general theory of planning. Policy Sciences(4), pp. 155-169. doi:https:// doi.org/10.1007/BF01405730

Sanders, E. B.-N., \& Stappers, P. J. (March de 2008). Co-creation and the New Landscapes of Design. Codesign, 1, pp. 5-18. Walker, J., \& Judy, A. (1989). Design History and the History of Design.London: Pluto Press.

Woolley-Barker, Tamsin. Teeming: How superorganisms work to build infinite wealth in a finite world (and your company to). Ashland, Oregon: White Cloud Press, 2017.

Yelavich, Susan. Contemporary world interiors. London: Phaidon, 2007 